\title{
QUEEN'S
UNIVERSITY
BELFAST
}

\section{Prediction of pressure drop in multiphase horizontal pipe flow}

Spedding, P. L., Benard, E., \& Donnelly, G. (2006). Prediction of pressure drop in multiphase horizontal pipe flow. International Communications in Heat and Mass Transfer, 33 (9)(9), 1053-1062.

https://doi.org/10.1016/j.icheatmasstransfer.2006.05.004

\section{Published in:}

International Communications in Heat and Mass Transfer

\section{Queen's University Belfast - Research Portal:}

Link to publication record in Queen's University Belfast Research Portal

\section{General rights}

Copyright for the publications made accessible via the Queen's University Belfast Research Portal is retained by the author(s) and / or other copyright owners and it is a condition of accessing these publications that users recognise and abide by the legal requirements associated with these rights.

Take down policy

The Research Portal is Queen's institutional repository that provides access to Queen's research output. Every effort has been made to ensure that content in the Research Portal does not infringe any person's rights, or applicable UK laws. If you discover content in the Research Portal that you believe breaches copyright or violates any law, please contact openaccess@qub.ac.uk. 
Provided for non-commercial research and educational use only. Not for reproduction or distribution or commercial use.

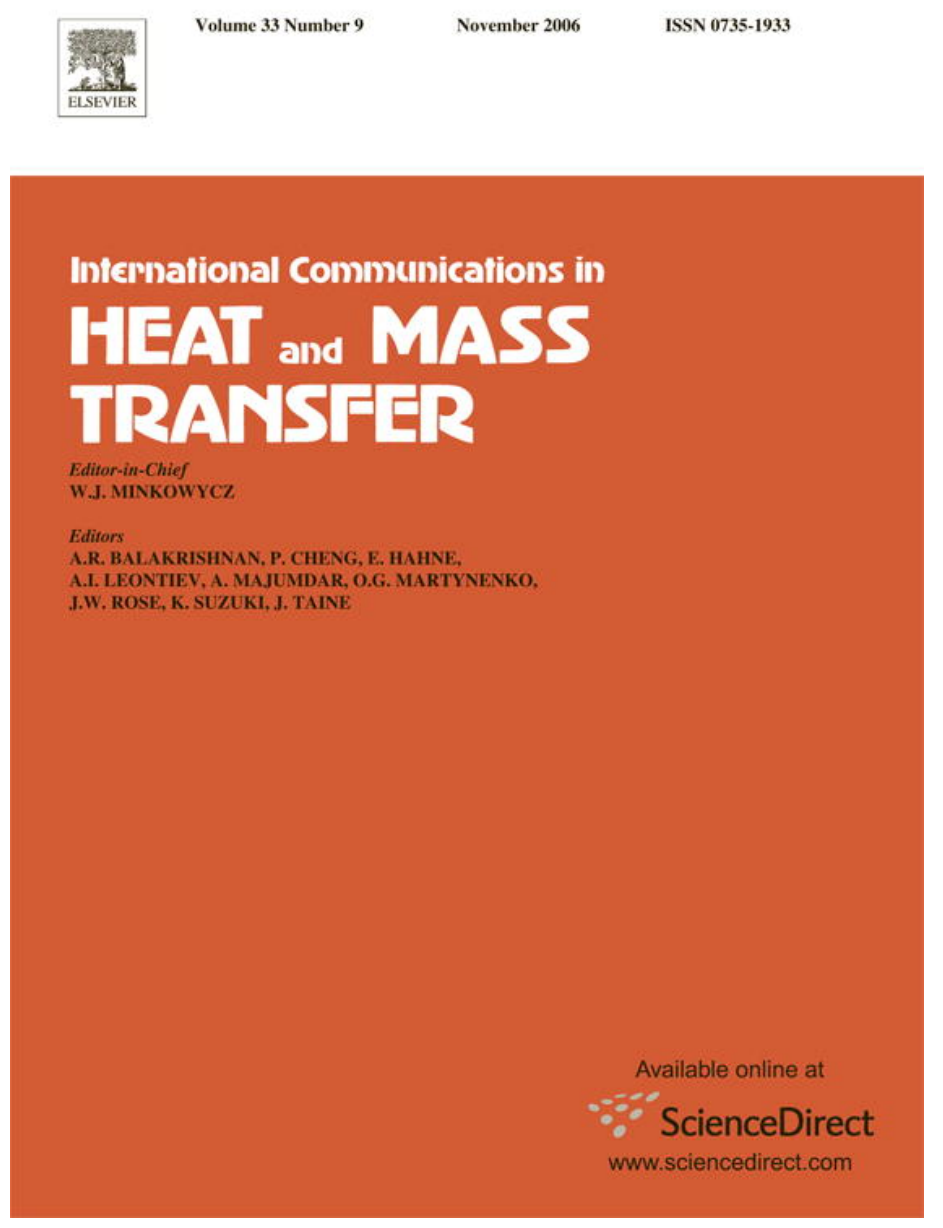

This article was originally published in a journal published by Elsevier, and the attached copy is provided by Elsevier for the author's benefit and for the benefit of the author's institution, for non-commercial research and educational use including without limitation use in instruction at your institution, sending it to specific colleagues that you know, and providing a copy to your institution's administrator.

All other uses, reproduction and distribution, including without limitation commercial reprints, selling or licensing copies or access,

or posting on open internet sites, your personal or institution's website or repository, are prohibited. For exceptions, permission may be sought for such use through Elsevier's permissions site at: 


\title{
Prediction of pressure drop in multiphase horizontal pipe flow ${ }^{2}$
}

\author{
P.L. Spedding *, E. Benard, G.F. Donnelly \\ School of Mechanical and Aerospace Engineering, Queen's University Belfast, Ashby Building, \\ Stranmillis Road, Belfast BT9 5AH, UK
}

Available online 20 September 2006

\begin{abstract}
Empirical correlations were tested against reliable two phase pipe flow data for the prediction of pressure drop. Correlations are recommended for the prediction with stratified and annular type flows. When these correlations were adapted to three phase gaswater-oil pipe flow in general they predicted for intermittent slug type flows. Momentum balance models could not be successfully adapted to the prediction of pipe three phase pressure drop.
\end{abstract}

(c) 2006 Elsevier Ltd. All rights reserved.

Keywords: Pressure drop; Two phase; Three phase; Pipe flow; Prediction

\section{Introduction}

Homogeneous and separated flow models have proven to be of limited value in the prediction of two phase frictional pressure loss in horizontal pipe flow [1]. Consequently empirical correlations have been proposed for prediction in gas-liquid flows some of which have been adapted to predict gas-water-oil three phase flow pressure drop by treating the combined liquid phase as a single entity. Some workers have claimed that adapted two phase correlations under estimate the pressure loss of three phase systems [2,3]. However, Fayed and Otten [4] adapted the Dukler-WicksCleveland [5] and Beggs-Brill [6] two phase correlations and found that they over predicted Sl and Fr flow and under predicted B flow in the three phase situation. Schlichting [7] adapted the Lockhart-Martinelli model [8] to three phase pressure loss prediction but Hall [9] claimed the resulting correlation was of limited value. Other workers [10,11] suggested current empirical methods of predicting three phase pressure loss were inadequate and a more rigid approach was required based on momentum balance models $[9,11]$.

In this work reliable two phase gas-liquid [12-18] and three phase gas-water-oil [9,18-23] data were used to test the validity of a number of two phase correlations that have been adapted to the prediction of pressure drop in three phase. While the liquid phases have been treated as a single entity some estimation also is required of the viscosity of

\footnotetext{
is Communicated by J.W. Rose and A. Briggs.

* Corresponding author.

E-mail address: e.benard@qub.ac.uk (P.L. Spedding).
} 


$\begin{array}{ll}\text { Nomenclature } \\ \text { A } & \text { Annular regime } \\ \text { B } & \text { Bubble regime } \\ \text { BTS } & \text { Blow through slug regime } \\ \text { D } & \text { Droplet regime } \\ \text { F } & \text { Film regime } \\ \text { Fr } & \text { Froth regime } \\ \text { i.d. } & \text { Internal diameter, } \mathrm{m} \\ \text { OD } & \text { Oil dominated } \\ \text { PD } & \text { Pressure drop Pam } \\ \text { R } & \text { Ripple regime } \\ \text { RW } & \text { Roll wave regime } \\ \text { Sl } & \text { Slug regime } \\ \text { St } & \text { Stratified regime } \\ \text { V } & \text { Velocity, m s }{ }^{-1} \\ \text { W } & \text { Wave regime } \\ \text { WD } & \text { Water dominated } \\ & \\ \text { Subscripts } \\ \text { G } & \text { Gas } \\ \text { S } & \text { Superficial }\end{array}$

the combined liquid phase. The two models which usually are employed are those by Brinkman [24] and by PalRhodes [25]. Results from the predictions will be selected to illustrate general trends obtained with the various correlations and model.

\section{Lockhart-Martinelli correlation}

\subsection{Two phase}

For two phase flow the Lockhart-Martinelli correlation [8] predicted the pressure drop with a wide scatter and most data were bounded within $\pm 40 \%$ spread with a likelihood of over prediction. Fig. 1 shows the over prediction worsened

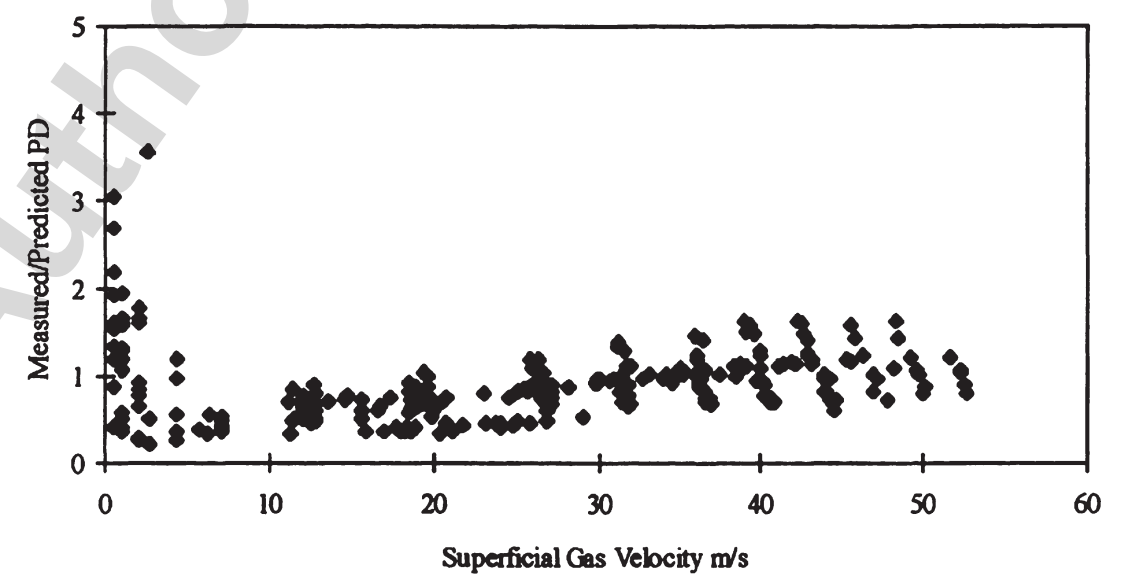

Fig. 1. Measured to predicted pressure drop against superficial gas velocity for the $0.0454 \mathrm{~m}$ i.d. Chen [14] data using the Lockhart-Martinelli [8] correlation. 


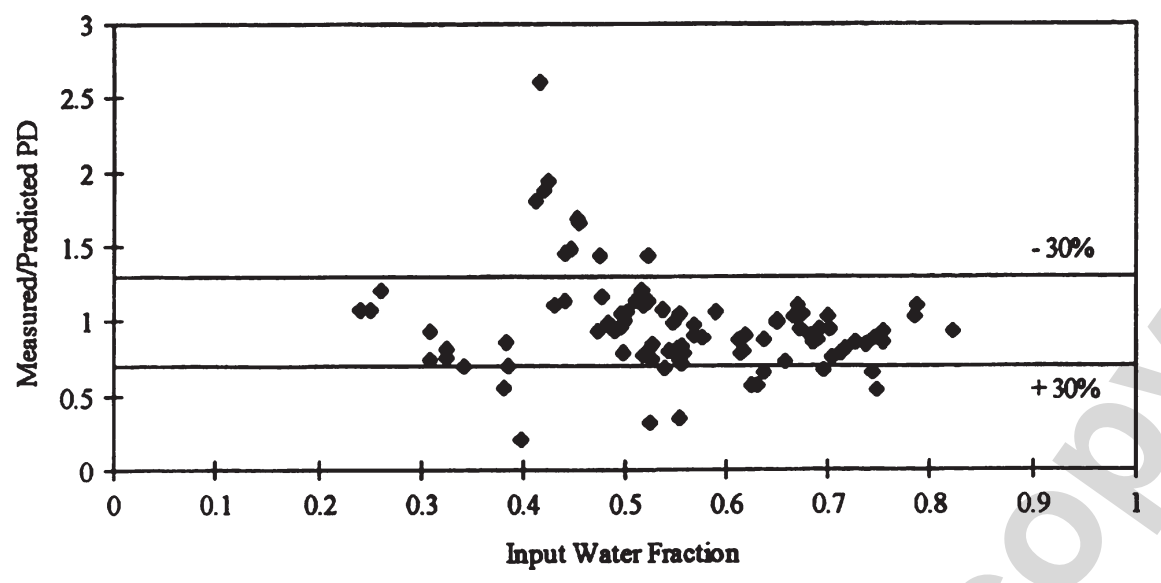

Fig. 2. Measured to predicted pressure gradient against input water fraction for the $0.079 \mathrm{~m}$ i.d. data of Hall [9] using the Lockhart-Martinelli correlation [8] and the Brinkman [24] model.

at low gas rates where the liquid hold-up was high with the S1 and BTS flow regimes. The $0.02515 \mathrm{~m}$ i.d. data of Andritsos [15] were under predicted around the $-40 \%$ mark, while the high pressure data of Andrews [12] were over predicted in excess of $60 \%$.

Spence and Spedding [26] suggested from a more limited database that the F+D and D regimes were predicted within a spread of $\pm 30 \%$ but it was not substantiated by this work.

\subsection{Three phase}

The three phase pressure loss of Donnelly [18] gave over prediction in excess of $70 \%$ in OD flows with a wide scatter in the WD region. The large diameter high pressure data of Lunde et al. [22] was grossly over predicted particularly at higher gas velocities. Performance of the correlation against the Sobocinski data [19] was poor with a high degree of scatter and general over prediction.

By contrast the Sl flow data exhibited better overall performance in contrast to the result for two phase flow. Fig. 2 shows that much of the three phrase Sl flow data of Hall [9] were predicted within $\pm 30 \%$. However there was a tendency to over prediction in the OD region while gross under prediction was in evidence around the inversion point. The Brinkman [24] viscosity model displayed a lower degree of scatter than other viscosity models. Both the

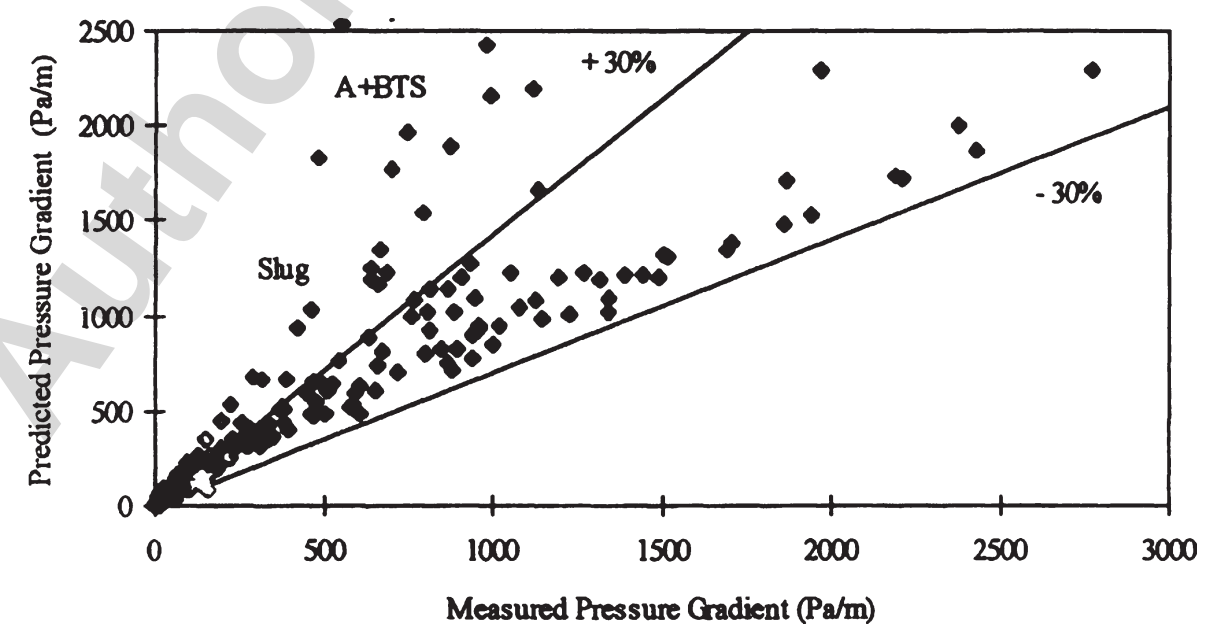

Fig. 3. Measured against predicted pressure loss for the $0.0454 \mathrm{~m}$ i.d. Nguyen [13] data using the Dukler-Wicks-Cleveland [5] correlation with the Eaton et al. [27] hold-up prediction. 


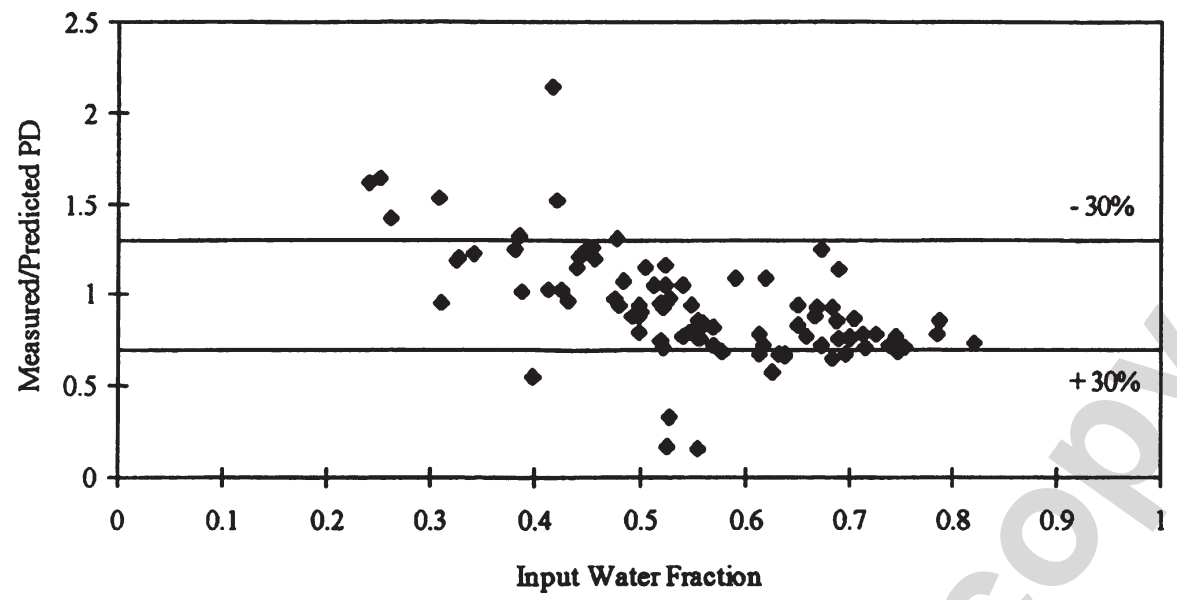

Fig. 4. Measured to predicted pressure loss for the $0.079 \mathrm{~m}$ i.d. data of Hall [9] using the Dukler-Wicks-Cleveland correlation [5] and Eaton et al. [27] hold-up correlation with the Brinkman [24] viscosity model.

Sl flow data of Malinowsky [20] and Laflin and Oglesby [21] showed a tendency to under prediction in OD flows and around the inversion point.

\section{Dukler-Wicks-Cleveland correlation}

\subsection{Two phase}

Best performance with the Dukler-Wicks-Cleveland correlation [5] was obtained when it was used in conjunction with the hold-up prediction model of Eaton et al. [27]. Against two phase data the correlation performed poorly with the majority of values being under estimated as shown in Fig. 3 for the $0.0454 \mathrm{~m}$ i.d. results of Nguyen [13]. In addition the Sl and A+BTS regimes were grossly over estimated with prediction deteriorating significantly at low gas velocities, low quality flow and for the Fr and D regimes. However the wave patterns generally were bounded within a $\pm 30 \%$ spread. The high pressure data of Andrews [12] while being mostly over predicted were still within the $\pm 30 \%$ margin.

\subsection{Three phase}

With the three phase data the Sl flow regime exhibited a low scatter except around the inversion point and in the OD region. The Malinowsky [20], Laflin and Oglesby [21] and Hall [9] results all exhibited this trend with the latter data

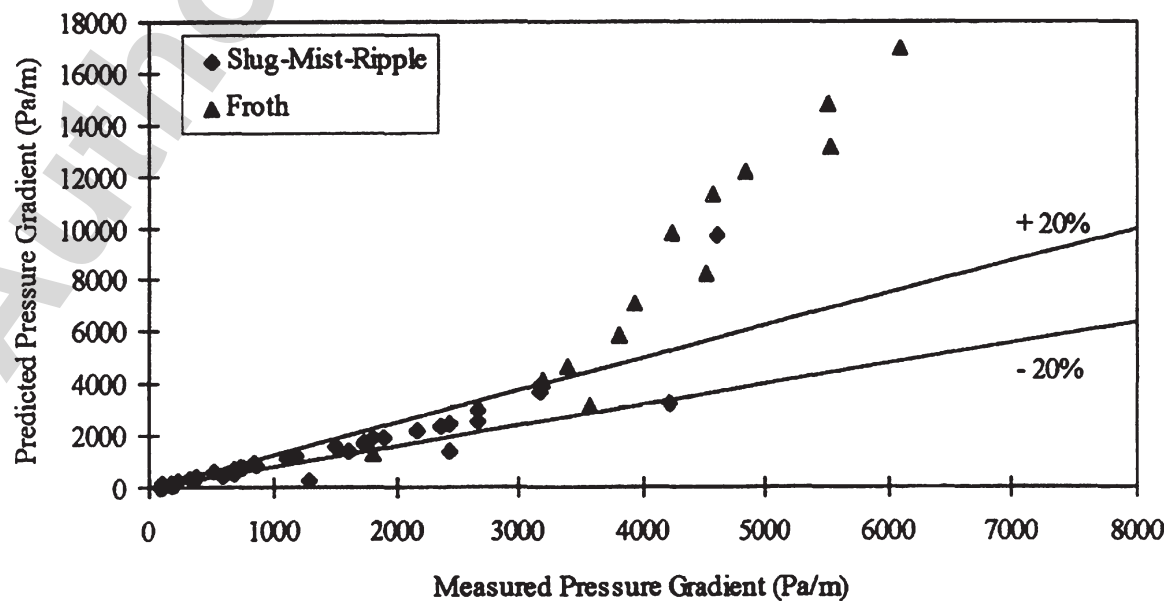

Fig. 5. Measured against predicted pressure drop for the $0.0525 \mathrm{~m}$ i.d. data of Andrews [12] using the Beggs-Brill [6] correlations. 


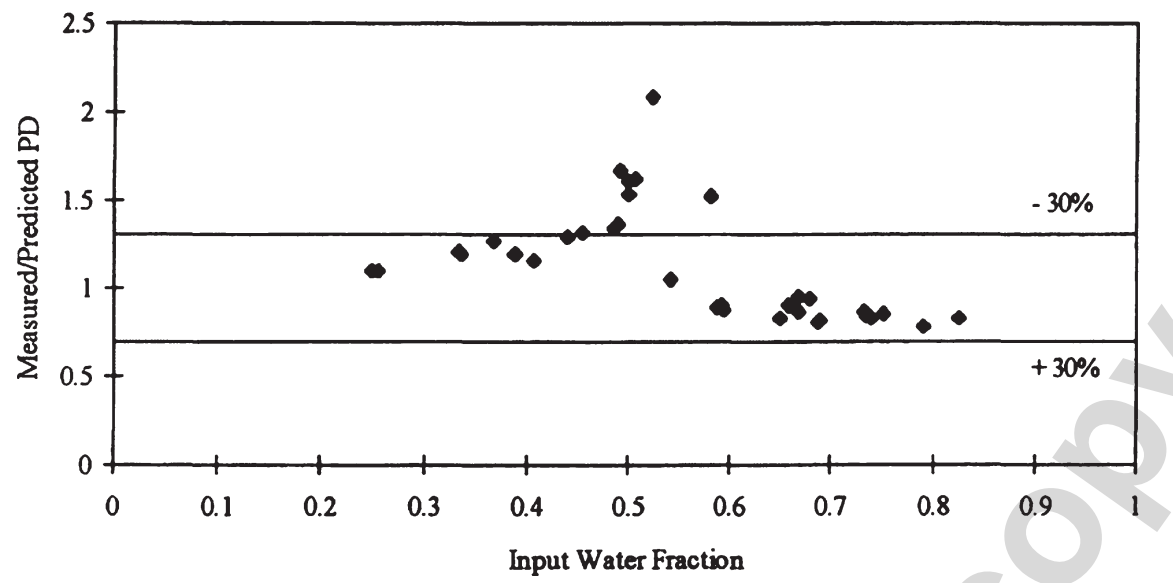

Fig. 6. Measured to predicted pressure drop against input water fraction for the $0.0381 \mathrm{~m}$ i.d. data of Malinowsky [20] using the Beggs-Brill [6] correlation.

showing in Fig. 4 an outcome that was similar to that obtained with the Lockhart-Martinelli correlation [8] in Fig. 2. There was little difference with the result obtained with the use of either the Brinkman [24] or Pal-Rhodes [25] viscosity models. The Sobocinski data [19] did not perform well with this correlation but the $0.0501 \mathrm{~m}$ i.d. data of Donnelly [18] and that by Lunde et al. [22] gave reasonable performance with $70-80 \%$ of the data falling with the $\pm 30 \%$ range.

\section{Beggs-Brill correlation}

\subsection{Two phase}

The correlation of Beggs-Brill [6] over predicted two phase pressure drop for most air-water data [13-18]. The error margin was lowered progressively with increasing pipe diameter and for the stratified regime. For example the high pressure observations of Andrews [12] given in Fig. 5 correlated within a $\pm 20 \%$ margin in the stratified flow regimes but were significantly over predicted for regimes in the droplet and mist flows.

\subsection{Three phase}

Prediction of three phase pressure loss using the Beggs-Brill [6] correlation led to gross scatter and over prediction with the $0.079 \mathrm{~m}$ i.d. Sobocinski [19] and $0.0259 \mathrm{~m}$ i.d. Donnelly [18] data. Performance was improved with an

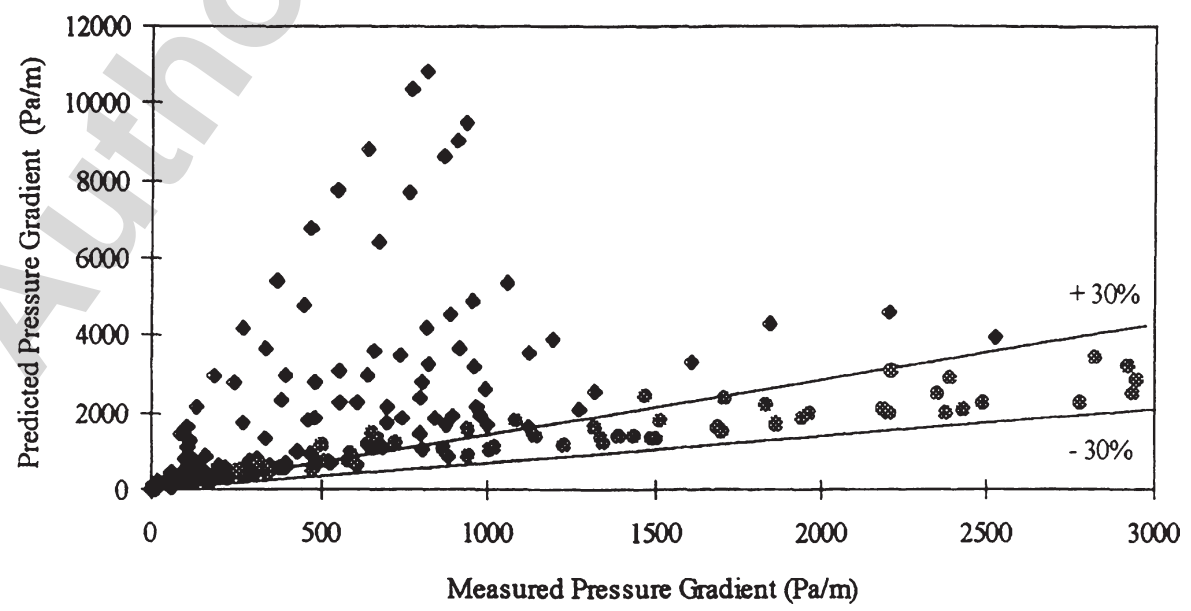

Fig. 7. Measured against predicted pressure loss for the $0.0454 \mathrm{~m}$ i.d. data of Nguyen [13] using the Friedel [28] correlation. 


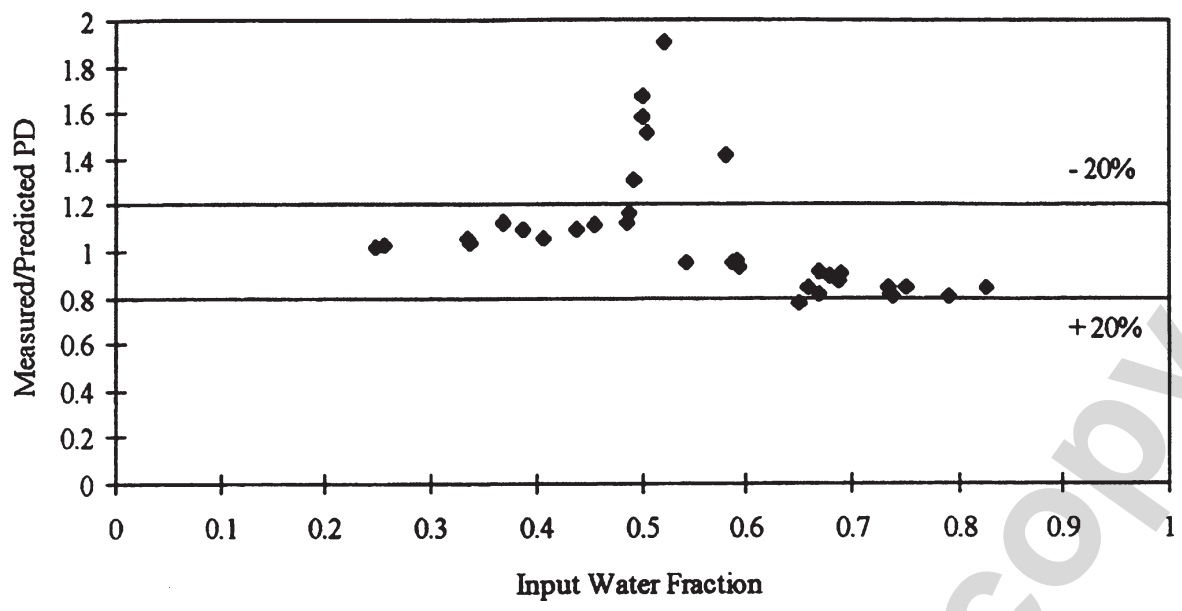

Fig. 8. Measured to predicted pressure loss against input water fraction for the $0.0381 \mathrm{~m}$ i.d. data of Malinowsky [20] using the Friedel correlation [28] and the Pal-Rhodes [25] viscosity model.

increase in pipe diameter as evidenced by the $0.0501 \mathrm{~m}$ i.d. Donnelly [18] data. There was an increase in scatter of the data when the Pal-Rhodes [25] viscosity model was used. For Sl flow [9,20,21] over prediction was noticeable in the WD region while under prediction was obtained in the OD region and particularly around the inversion point as shown in Fig. 6. Generally for Sl flow the majority of data was within a $\pm 30 \%$ spread. The Lunde et al. [22] data tended to be under predicted with a wide scatter.

\section{Friedel correlation}

\subsection{Two phase}

The Friedel correlation [28] gave significant over prediction of two phase pressure loss with a wide scatter. Nevertheless good performance within a $\pm 30 \%$ margin was obtained for high gas velocity flows in the $\mathrm{A}+\mathrm{D}$ and $\mathrm{A}+\mathrm{W}$ regimes as shown in Fig. 7 by selecting the Nguyen [13] 0.0454 m i.d. data.

\subsection{Three phase}

For three phase data that of Sobocinski [19] and the $0.0501 \mathrm{~m}$ i.d. results of Donnelly [18] were over estimated in excess of $70 \%$ and $50 \%$ respectively by the Friedel [28] correlation. An acceptable level of prediction was achieved for

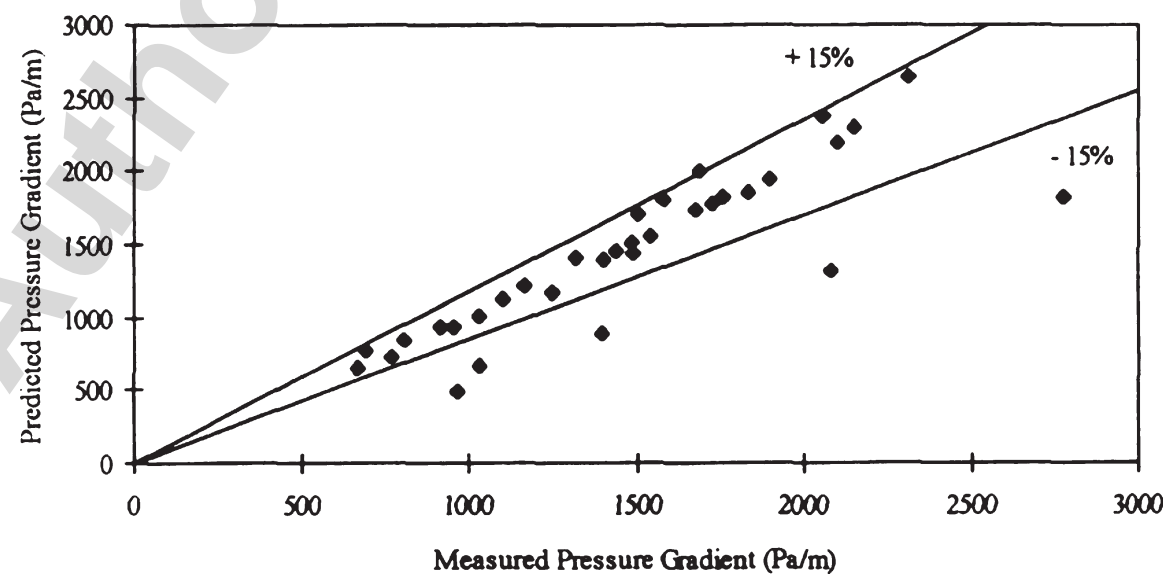

Fig. 9. Measured against predicted pressure loss for the $0.0381 \mathrm{~m}$ i.d. data of Malinowsky [20] using the Beattie-Whalley [29] correlation and the Brinkman [24] viscosity model. 


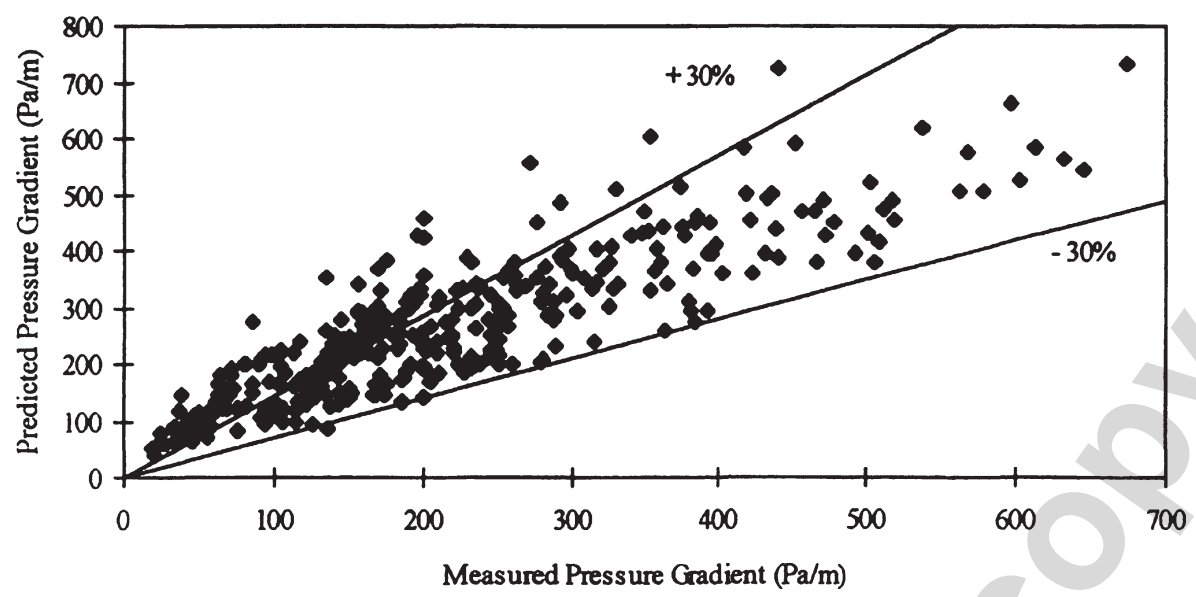

Fig. 10. Measured against predicted pressure loss for the $0.0501 \mathrm{~m}$ i.d. data of Donnelly [18] using the Beattie-Whalley [29] correlation and the Brinkman [24] viscosity model.

the majority of the Lunde et al. [22] data and the S1 flow regime [9,20,21]. Fig. 8 gives the result of prediction of the Malinowsky [20] data with a tendency to over prediction in the WD region, under prediction for OD flows and gross under prediction around the inversion. With the Friedel correlation [28] the Pal-Rhodes [25] viscosity model achieved a smaller spread of the majority of data than that obtained with the Brinkman [24] viscosity model (i.e. $\pm 20 \%$ against $\pm 30 \%$ ) with the exception that the spread at the inversion point was much larger.

\section{Beattie-Whalley correlation}

\subsection{Two phase}

The Beattie-Whalley [29] correlation gave a noticeable under prediction for small diameter tubes and an over prediction for large diameter pipes. The correlation performed badly for both Sl and A+BTS regimes at low and high gas velocities and high and low liquid hold-ups respectively. The Andrews [12] data was mostly found to be under predicted.

\subsection{Three phase}

By contrast there was an improvement in performance for three phase pressure loss prediction. The Sl flow data $[9,20,21]$ displayed a reasonable performance being mainly within a narrow spread as illustrated in Fig. 9. Other three

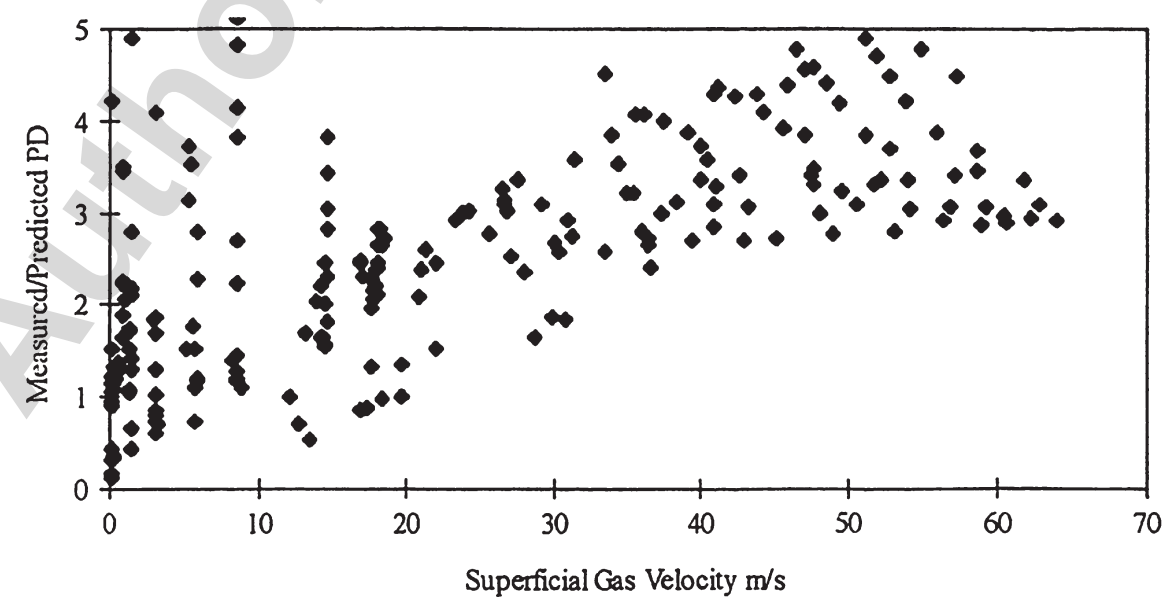

Fig. 11. Measured to predicted pressure loss against gas velocity for the $0.0454 \mathrm{~m}$ i.d. data of Nguyen [13] using the Muller Steinhagen-Heck [30] correlation. 


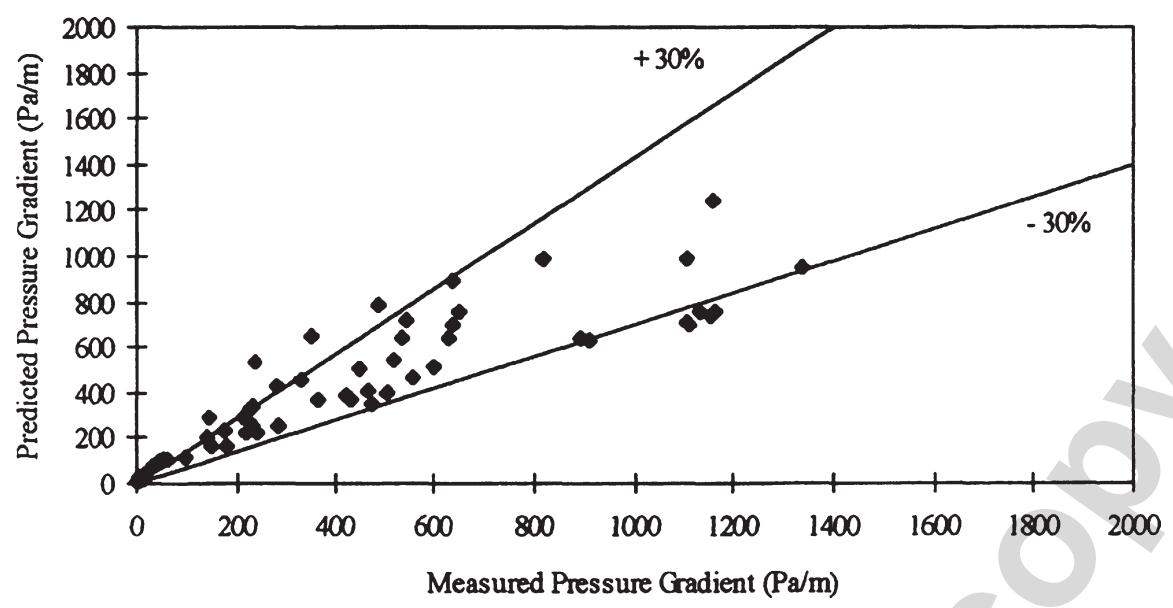

Fig. 12. Measured against predicted pressure gradient for the stratified data for $0.0259 \mathrm{~m}$ i.d. pipe by Donnelly [18] using the Olujic [31] correlation.

phase data $[18,19]$ gave a high degree of scatter with a tendency to over predict as shown in Fig. 10. The Lunde et al. [22] result was grossly under predicted by the correlation. The Brinkman [24] velocity model gave the best result with this correlation.

\section{Muller Steinhagan-Heck correlation}

\subsection{Two phase}

For two phase pressure loss the Muller Steinhagen-Heck [30] correlation gave gross under prediction over the entire range of flow regimes. Fig. 11 indicates that performance progressively deteriorated with increasing gas velocity.

\subsection{Three phase}

For three phase pressure loss data the correlation gave even worse results with unacceptably low pressure loss predictions.

\section{Olujic correlation}

\subsection{Two phase}

Only St type flow data for pipe under about $0.05 \mathrm{~m}$ i.d. gave acceptable pressure loss prediction with the Olujic [31] correlation. Fig. 12 illustrates that the St data by Donnelly [18] for $0.0259 \mathrm{~m}$ i.d. pipe were mainly bounded within a $\pm 30 \%$ spread. The data for other flow regimes by Donnelly [18] had a variance of $\pm 60 \%$. Intermittent S1 type regimes were particularly poorly predicted. Ferguson and Spedding [1] suggested from a very limited database that as well as the St flow regimes the Olujic [31] correlation predicted the A and D patterns but these latter were not substantiated in this work.

\subsection{Three phase}

The three phase data were particularly poorly predicted by this correlation.

\section{Momentum balance models}

Two phase momentum balance models have already been the subject of an evaluation study [32] which emphasised the importance of the shape of the gas/liquid interface in the determination of pressure drop. 


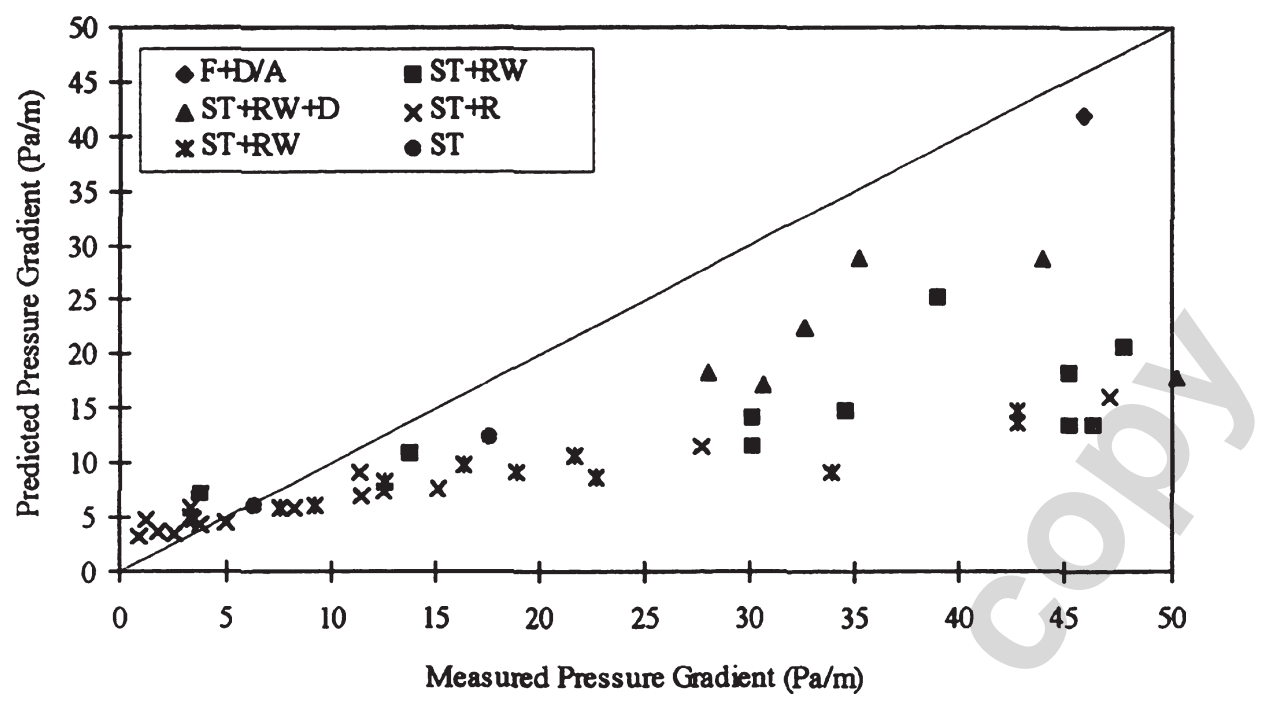

Fig. 13. Measured against predicted pressure loss for the $0.079 \mathrm{~m}$ i.d. Sobocinski [19] data when using the momentum balance model of Hall [9].

Hall [9] specifically developed a three phase momentum balance model albeit by extension of the Taitel and Dukler [33] two phase momentum balance model. The result was a gross under prediction of three phase pressure drop as evidenced by the Sobocinski [19] $0.079 \mathrm{~m}$ i.d. data presented in Fig. 13. Failure can again be ascribed to neglect of the shape of the gas/liquid interface shape etc.

\section{Discussion}

Prediction of two phase pressure drop by any of the chosen correlations was not successful over all flow regimes. Overall the Beattie-Whalley [29] correlation gave the best average prediction of all the data tested but there was a wide spread to the individual predictions obtained. Prediction was particularly poor with intermittent Sl type flow patterns for all the correlations. However the Duklar-Wicks-Cleveland [5], Beggs-Brill [6] and Olujic [31] correlations were successful in predicting St type regimes within a $\pm 30 \%$ spread while the Friedel [28] correlation similarly handled A type flows.

For three phase flow pressure prediction none of the adapted correlations were successful for all the flow regimes. Under prediction was always achieved around the inversion point. In order of performance the Friedel [28], BeattieWhalley [29], Dukler-Wicks-Cleveland [5] and Beggs-Brill [6] were successful with prediction for Sl flow patterns within a $\pm 30 \%$ range away from the inversion point. With each of these correlations the WD region was over predicted and the OD region under predicted. In general the Brinkman [24] viscosity model gave the best results but the Friedel [28] correlation performed best with the Pal-Rhodes [25] model. None of the adapted correlations performed satisfactorily while predicting the separated flow patterns.

Thus there was a contrast between the prediction performance of the correlations between two phase and three phase flow. Correlations that performed better with two phase separated flow [5,6,26,31] and poorly with two phase intermittent regimes, gave reversed poor and reasonable three phase performance respectively.

Prediction of pressure drop by adaption of momentum balance models to three phase operation would be expected to be improved by the inclusion of the oil phase to smooth the liquid-gas interface but the opposite was found. Attention must therefore be directed to obtaining realistic expressions for liquid wall shear stresses and the interfacial shear stress if prediction performance of momentum balance models are to be improved for three phase pipe flows.

\section{Conclusions}

Detailed experimental data have been used to demonstrate that pressure drop prediction methods used for two and three phase pipe flow are useful only for particular flow regimes. Two phase St flows can be predicted within a $\pm 30 \%$ spread by three correlations $[5,6,29]$ while the A flows can be predicted by one correlation [28].

Four adapted correlations $[5,6,26,31]$ allowed for prediction of three phase intermittent S1 type flows. Existing two phase moment balance models could not be successfully adapted to three phase flow. 


\section{References}

[1] M.E.G. Ferguson, P.L. Spedding, Measurement and prediction of pressure drop in two phase flow, J. Chem. Technol. Biotechnol. 62 (1995) $262-278$.

[2] A. Pleshko, M.P. Sharma, An experimental study of vertical three phase (oil-water-air) upward flow, Proc. ASME. Conf. Advances in GasLiquid Flows FED 99, HTD 155, 1990, pp. 97-108.

[3] G.A. Gregory, M. Frogassi, A critical evaluation of multiphase gas liquid pipeline calculation methods, Int. Conf. Multiphase Flow, London 2 (1995) 93-108.

[4] A.S. Fayed, L. Otten, Comparing measured and calculated multiphase flow pressure drop, Oil Gas J. (Aug 1983) 136-144.

[5] A.E. Dukler, M. Wicks, R.G. Cleveland, Pressure drop and hold-up in two-phase flow, AIChEJ 10 (1964) 38-51.

[6] H.D. Beggs, J.P. Brill, A study of two phase flow in inclined pipes, Trans. Pet. Soc. AIME 25 (1973) 607-617.

[7] P. Schlichting, The Transport of oil-water-gas mixtures in oil field gathering systems, Erdol-Ergas Zeitschrift 86 (1971) $235-249$.

[8] R.W. Lockhart, R.C. Martinelli, Proposed correlation of data for isothermal two-phase, two component flow in pipes, CEP 45 (1) (1949) $39-49$.

[9] A.R.W. Hall, Multiphase flow of oil, water and gas in horizontal pipes. PhD Thesis, Univ. London, 1992.

[10] H. Stapelberg, D. Mewes, The flow of two immiscible liquids and air in a horizontal pipe, Proc. ASME Conf. Advances in Gas-Liquid Flows FED 99, HTD 155, 1990, pp. 89-96.

[11] Y. Taitel, D. Barnea, J.P. Brill, Stratified three phase flow in pipes, Int. J. Multiphase Flow 21 (1995) 53-60.

[12] D.E. Andrews, The prediction of pressure loss during two phase horizontal flow in two-inch line pipe. MSc Thesis, Univ. Texas, 1966.

[13] V.T. Nguyen, Two phase gas-liquid co-current flow. An investigation of holdup, pressure drop and flow pattern in a pipe at various inclinations. PhD Thesis, Univ. Auckland, 1975.

[14] J.J.J. Chen, Two phase gas liquid flow with particular emphasis on holdup measurements and predictions. PhD Thesis, Univ. Auckland, 1979.

[15] N. Andritsos, Effect of pipe diameter and liquid viscosity on horizontal stratified flow. PhD Thesis, Univ, Illinois, Urbana, 1986.

[16] N.P. Hand, Gas-liquid co-current flow in a horizontal pipeline. PhD Thesis, Queen's University Belfast, 1991.

[17] M.E.G. Ferguson, An investigation of horizontal and inclined two phase pipe flow. PhD Thesis, Queen's University Belfast, 1993.

[18] G.F. Donnelly, An analytical evaluation of horizontal multiphase flow. PhD Thesis, Queen's University Belfast, 1997.

[19] D.P. Sobocinski, Horizontal co-current flow of water-gas-oil and air. MSc Thesis, Univ. Oklahoma, 1958.

[20] M.S. Malinowski, An experimental study of oil-water and air-oil-water flowing mixtures in horizontal pipes. MSc Thesis, Univ. Tulsa, 1976.

[21] G.C. Laflin, K.D. Oglesby, An experimental study on the effects of flow rate, water fraction and gas-liquid ratio on air-oil-water flow in horizontal pipes. MSc Thesis, Univ. Tulsa, 1976.

[22] K. Lunde, S. Nuland, M. Lingelem, Aspects of three phase flow in gas condensate pipe-lines, 30th European Two Phase Flow Group Meeting, 1993, Paper 11.

[23] L. Pan, S. Jayanti, G.F. Hewitt, Flow patterns, phase inversion and pressure gradient in air-oil-water flow in a horizontal pipe, Int. Conf. Multiphase Flow 2 (1995) 1-8.

[24] H.C. Brinkman, The viscosity of concentrated suspensions and solutions, J. Chem. Phys. 20 (1975) 571-594.

[25] R. Pal, E. Rhodes, A novel viscosity correlation for non-Newtonian concentrated emulsions, J. Colloid Interface Sci. 107 (1985) $301-307$.

[26] D.R. Spence, P.L. Spedding, Prediction of pressure loss in horizontal two phase flow, Proc. Inst. Chem. Eng. Symp. 1 (1988) $15-34$.

[27] B.A. Eaton, D.E. Andrews, C.R. Knowles, I.H. Silberberg, K.E. Brown, The prediction of flow patterns, liquid hold-up and pressure losses occurring during continuous two phase flow in horizontal pipelines, J. Pet. Technol. 19 (June 1967) 815-823.

[28] L. Friedel, Improved friction pressure drop correlation for horizontal and vertical two phase, Eur. Two Phase Flow Group Meeting, 1979 , Paper E2.

[29] D.R.H. Beattie, P.B. Whalley, A simple two phase frictional pressure drop calculation method, Int. J. Multiphase Flow 8 (1982) $83-87$.

[30] H. Muller Steinhagan, K. Heck, A simple friction pressure drop correlation for two phase flow in pipes, C.E.P. 20 (1986) $297-308$.

[31] Z. Olujic, Predicting two phase flow friction loss in horizontal pipes, Chem. Eng. (June 24 1985) 45-50.

[32] J.S. Cole, G.F. Donnelly, P.L. Spedding, Trials of momentum balance for two phase horizontal pipe flow, Int. Commun. Heat Mass Transf. 31 (2004) 919-927.

[33] Y. Taitel, A.E. Dukler, A model for predicting flow regime transactions in horizontal and near horizontal gas-liquid flow, AIChEJ 22 (1976) $47-55$. 